\title{
Kinetic and Surface Mechanisms to Growth of Hexagonal Boron Nitride
}

\author{
Patrícia R. R. Barreto, Alan E. Kull ${ }^{\dagger}$, Mark A. Cappelli ${ }^{\dagger}$ \\ Laboratório Associado de Plasma, Instituto Nacional de Pesquisas Espaciais, \\ São José dos Campos, SP, CP 515, 12201-970, Brazil \\ ${ }^{\dagger}$ Mechanical Engineering Department, Stanford University, \\ Stanford, CA 94305-3032, USA
}

\begin{abstract}
A mechanism is presented for the gas-phase chemistry and surface reactions describing the growth of boron nitride films. The gas phase mechanism includes 33 species and 216 elementary reactions. Rate parameters for 117 elementary reactions were obtained from published experimental/theoretical data and those for the other 99 were determined using transition state theory. The mechanism examined here is an extension and update of a previous mechanism that contained 26 species and 67 elementary reactions. Standard reaction flux/pathway and gradient sensitivity analysis techniques are used to identify important reaction pathways. The calculations were handled through the use of the ChemKin software package. The model was applied to the growth of hexagonal boron nitride in an arcjet plasma source operating on mixture of $\mathrm{BF}_{3}, \mathrm{H}_{2}$ and $\mathrm{N}_{2}$. From the growth rate and experimental conditions for such reactors, this work demonstrates that species with mole fractions in the range of $1 \times 10^{-10}-2 \times$ $10^{-4}$ (easily generated by gas-phase conditions) can account for the measured growth rate. A comparison of the predicted mole fractions of the gas-phase species present for the experimental residence times with those required to account for the measured film growth rates allows us to identify possible growth precursors. At the experimental settings, it is found that the residence time of the reacting species does not allow the flow to reach the chemical equilibrium, and that many radicals other than the source gases can account for the measured $\mathrm{BN}$ growth rate. The gas-phase is shown to be removed from thermodynamic equilibrium. For comparison, the equilibrium mole fractions were also calculated using an available equilibrium chemistry solver, STANJAN. Growth rates of $10^{-9}$ to $10^{-6} \mathrm{~kg} \mathrm{~m}^{-1} \mathrm{~s}^{-1}$ were measured for a wide range of $\mathrm{H}_{2}, \mathrm{BF}_{3}$ and $\mathrm{NF}_{3}$ flux. Both the finite-rate kinetics and equilibrium calculations confirm the importance of added hydrogen to facilitate boron nitride condensation from the gas phase. A simple surface mechanism with 7 steps is proposed with rate constants chosen to best fit the experimental growth kinetics. The results of the model, with surface rate coefficients determined from analogous gas-phase reactions, tuned slightly to agree with the experimental growth rates for $\mathrm{BF}_{\mathrm{x}}, \mathrm{x}=1,2$ or 3 , as the rate-limiting growth precursor. It is also shown that the hydrogen atom has a great influence in the growth rate and that fluorine atom etches the $\mathrm{hBN}$ films.
\end{abstract}

\section{INTRODUCTION}

Recently, there has been considerable interest in the growth of boron nitride (BN) films. Like carbon, boron nitride has different allotropes, the most common of which are the hexagonal $(\mathrm{hBN})$ and cubic $(\mathrm{cBN})$ phases. The hexagonal phase, although electrically insulating, has properties very similar to graphite while cubic phase has properties comparable to diamond.

At present there is little understanding of the chemical processes that are involved in, and which processes the synthesis of either hexagonal or cubic boron nitride from the vapor phase. 
Theoretical research found in the literature includes thermodynamic equilibrium calculations for mixtures involving $\mathrm{B} / \mathrm{F} / \mathrm{N} / \mathrm{H}[1-5]$ and $\mathrm{B} / \mathrm{Cl} / \mathrm{N} / \mathrm{H}[4,5]$, as well as limited kinetics studies of the reactions between $\mathrm{BCl}_{3}$ and $\mathrm{NH}_{3}[6,7]$.

Detailed experimental studies of the kinetics of hexagonal boron nitride growth from heated $\mathrm{BF}_{3}, \mathrm{NH}_{3}$ and $\mathrm{Ar}$ mixtures have been reported by Prouhet et al. [8, 9]. In that study, the growth rates were measured for a wide range of temperature, flow rates, and pressure. Although direct measurements of vapor phase reactants over the substrate were not reported, there was sufficient data presented that allows a first attempt at modeling the gas-phase and possible surface reactions. In previous studies [8], an analysis of the conditions of the experiments of Prouhet et al. $[9,10]$ was made and it was shown that in addition to the initial reactant gases, other minor radical and stable species are produced in the gas phase in sufficient quantities to influence and account for the boron nitride growth rates that are observed. It was also shown that these possible rate limiting growth precursors are not unique, and that if the precursor gas-phase radicals react with the surface at rates comparable to that of analogous gas-phase rates, the growth rates predicted on the basis of a relatively simple surface mechanism are found to capture the trends seen in the experiments over a range of temperature and pressure where the growth rates are surface reaction-rate limited. Using these data we have described the first kinetic mechanism [8] and have shown that the gas-phase in this hot-walled flow reactor is removed from chemical equilibrium, and that many radicals other than the source gases can account for the measured $\mathrm{hBN}$ growth rates. After that we have applied the same mechanism to explain the growth of boron nitride throw an arcjet using $\mathrm{BF}_{3}, \mathrm{~N}_{2}, \mathrm{H}_{2}$ and $\mathrm{NF}_{3}$ mixtures $[8,11,12]$

\section{KINETIC MECHANISM}

A kinetic mechanism is presented for the gas-phase chemistry of a $\mathrm{Ar} / \mathrm{B} / \mathrm{F} / \mathrm{H} / \mathrm{N}$ system to describe the growth of boron nitride films. The gas-phase kinetic mechanism is comprised of 33 species with 216 elementary reactions $[12,13,14]$. Rate parameters for 117 elementary reactions were obtained from published experimental/theoretical data and those for the other 99 were estimated using transition state theory. The mechanism examined here is an extension and update of a previous mechanism that contained 26 species and 67 elementary reactions $[8,11]$. The rate coefficients are determined as a function of temperature and written down in the Arrhenius form $\left(\mathrm{k}_{\mathrm{f}}=\mathrm{A} \mathrm{T}^{\mathrm{n}} \exp \left(-\mathrm{E}_{\mathrm{a}} / \mathrm{RT}\right)\right)$.

An arc discharge operating on $\mathrm{N}_{2} / \mathrm{H}_{2}$ mixture and in the $1-2 \mathrm{~kW}$ power range was expanded to low densities by way of a converging-diverging nozzle. The $\mathrm{BF}_{3}$ and $\mathrm{NF}_{3}$ were injected into the disassociated jet, and the reactive plasma. The molecular nitrogen and hydrogen were assumed to be $\sim 30 \%$ dissociated in atomic nitrogen and hydrogen. The plasma jet was treated as one-dimensional flow so that the gas temperature and species concentration depend only on the distance along the flow reaction chamber. The experimental condition are: estimated temperature of $2000-3000 \mathrm{~K}$, flow velocity of $3000-8000 \mathrm{~m} / \mathrm{s}$, reactor pressure $200-300$ mtorr, and total gas flow of $7.0-8.0 \mathrm{slm}$. The typical residence time for the arcjet is $10-30 \mu \mathrm{s}$, according to experimental conditions, like pressure, electric power, gas flow and substrate position. It is found that this range of residence time does not allow the flow to reach equilibrium at the reactor condictions. For similar residence times, temperatures and pressures, it has been found that mixtures of methane and hydrogen in thermal vapor deposition systems used to grow diamond films also falls short of reaching equilibrium gas-phase conditions $[15,16,17]$. 
The growth rate, $\dot{\mathrm{G}}$, is expressed in terms of the arrival rate (due to random molecular motion at the substrate surface) of the rate-limiting boron or nitrogen containing species:

$$
\dot{\mathrm{G}}=\rho \chi_{\mathrm{j}} \Gamma_{\mathrm{j}} \gamma\left(\frac{\mathrm{m}_{\mathrm{BN}}}{\mathrm{m}_{\mathrm{i}}}\right)
$$

where: $\rho$ is the gas density, $\chi_{\mathrm{j}}$ and $\Gamma_{\mathrm{j}}$ are the molar fraction and the flux for the $\mathrm{j}$ species $\left(\Gamma_{i}=\bar{c}_{j} m_{j} / 4\right)$, that represents the growth species, respectively, $\bar{c}_{j}$ is the mean velocity $\left.\left(\bar{c}_{j}=\sqrt{8 \mathrm{k}_{\mathrm{B}} \mathrm{T} /\left(\pi \mathrm{m}_{\mathrm{j}}\right.}\right)\right), \mathrm{m}_{\mathrm{j}}$ is the mass for the $\mathrm{j}$ species, $\mathrm{k}_{\mathrm{B}}$ is the Boltzmann constant, $\mathrm{T}$ is the temperature, $\gamma$ is the reaction probability, $\mathrm{m}_{\mathrm{BN}}$ is the boron nitride mass and $\mathrm{m}_{\mathrm{i}}$ denotes the mass the i species

From the experimental growth rates and experimental conditions of the arcjet flows investigated below, one can determine which species with mole fractions in the range of $1 \times 10^{-11}$ $-1 \times 10^{-8}$ (easily generated by gas-phase conditions) can account for the measured growth rates if their reaction probabilities are near unity. It is not uncommon for reactive species such as atomic or molecular radicals to react on surfaces with high probabilities $(>0.01)$ at high temperatures. It was found that for the decomposition of boron and nitrogen-containing source gases the gas phase chemistry was removed from equilibrium, and many radicals were present at superequilibrium concentrations.

To aid in carrying out the gas-phase kinetics calculations, we make use of the ChemKin software package [17] which provides, in addition to a robust numerical procedure for treating relatively stiff ordinary differential equations, a convenient user interface for entry of a detailed gas-phase mechanism. Rate constants for the reverse reactions are calculated using thermodynamic data from the ChemKin data base [18]. For comparison, the equilibrium mole fractions were also calculated using an available equilibrium chemistry solver, STANJAN [19].

Comparing the mole fraction obtained using the previous mechanism, 26 species and 67 reactions and the new mechanism, 33 species and 216 reactions, it is observed a higher dissociation rate of the $\mathrm{BF}_{3} \Rightarrow \mathrm{BF}_{2} \Rightarrow \mathrm{BF} \Rightarrow \mathrm{B}$, with the decreasing of the mole fraction of $\mathrm{BF}_{3}$ and the increasing of the mole fraction of $\mathrm{BF}_{2}, \mathrm{BF}, \mathrm{B}$ and also $\mathrm{F}$, because the most of the new reactions are in the $\mathrm{B} / \mathrm{F}, \mathrm{B} / \mathrm{F} / \mathrm{H}$ and $\mathrm{N} / \mathrm{F}$ subsystem.

Figure 1 compares the required mole fractions (assuming unity reaction probability) for nitrogen or boron-containing species, to account for the observed growth rates (using equation (1)) with the mole fraction obtained with the kinetic mechanism as a function of $\mathrm{H}_{2}, \mathrm{BF}_{3}$ and $\mathrm{NF}_{3}$ for $\mathrm{N}_{2}=7 \mathrm{slm}, \mathrm{BF}_{3}=50 \mathrm{sccm}$, and $\mathrm{NF}_{3}=50 \mathrm{sccm}$ (figure 1a), $\mathrm{N}_{2}=7 \mathrm{slm}, \mathrm{H}_{2}=504 \mathrm{sccm}$, and $\mathrm{NF}_{3}=50 \mathrm{sccm}$ (figure 1b), $\mathrm{N}_{2}=7 \mathrm{slm}, \mathrm{H}_{2}=504 \mathrm{sccm}, \mathrm{BF}_{3}=50 \mathrm{sccm}$ (figure 1c), respectively and $p=235$ mtorr. For clarity, only species with mole fractions higher than $1.0 \times 10^{-12}$ are shown.

It is apparent that over most of the entire range of gas flow shown, in addition to the primary reactant gases $\left(\mathrm{BF}_{3}, \mathrm{~N}_{2}\right.$ and $\left.\mathrm{NF}_{3}\right), \mathrm{BF}, \mathrm{BF}_{2}, \mathrm{BHF}_{2}$ and $\mathrm{N}$ can also be possible growth precursors, present at mole fractions well above those required to account for the growth rates. It is noteworthy that over experimental conditions, atomic hydrogen is present only as a minor species (mole fractions ranging from $2.8 \times 10^{-3}$ to $7.3 \times 10^{-2}$ ) however, as in the case of diamond film synthesis, it is known that atomic hydrogen (and perhaps also atomic fluorine in this case) plays an important role in the surface chemistry [20]. 

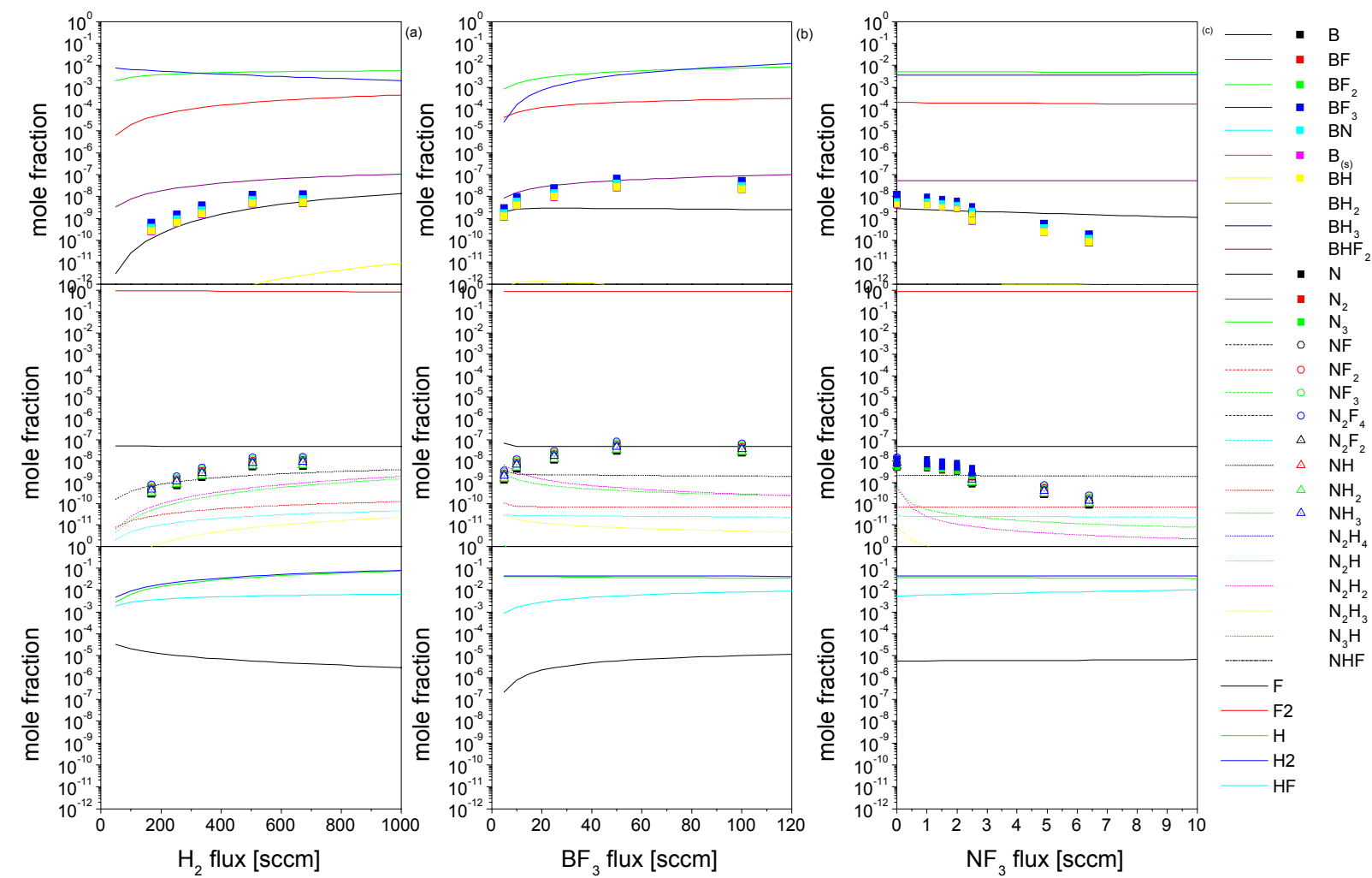

Figure 1: Substrate mole fraction obtained from the kinetic simulation (lines), and those required to account for the growth rate, equation (1) (symbols), as a function of gas flow for $\mathrm{N}_{2}=7 \mathrm{slm}$, $\mathrm{BF}_{3}=50 \mathrm{sccm}$, and $\mathrm{NF}_{3}=50 \mathrm{sccm}$ (figure 2a), $\mathrm{N}_{2}=7 \mathrm{slm}, \mathrm{H}_{2}=504 \mathrm{sccm}$, and $\mathrm{NF}_{3}=50 \mathrm{sccm}$ (figure 2b), $\mathrm{N}_{2}=7 \mathrm{slm}, \mathrm{H}_{2}=504 \mathrm{sccm}, \mathrm{BF}_{3}=50 \mathrm{sccm}$ (figure 2c), respectively and $\mathrm{p}=235$ mtorr.

\section{SURFACE MECHANISM}

A simple surface mechanism is proposed with rate constants chosen to best fit the experimental growth kinetics. From an analysis of the experimental conditions of the growth rate, a relatively simple surface mechanism (table I) based on $\mathrm{BF}_{3}, \mathrm{BF}_{2}$, or $\mathrm{BF}$ as possible growth precursors, was proposed. The mechanism provides for involvement of atomic hydrogen and fluorine $(\mathrm{H}, \mathrm{F})$ in abstraction, termination, incorporation, and etch reactions, and is found to capture the overall trends and magnitude of the growth rates over a wide range of conditions. The mechanism, which has 7 overall elementary reactions, is described before $[8,11,12,14]$.

The resulting analytical expression for the growth rate for hexagonal boron nitride is $[8$, $11,12,14]$ :

$$
\dot{G}_{h B N}=m_{B N} \frac{\left.k_{5}\left(k_{1} k_{3}[H]\left[P_{1}\right]-k_{2} k_{6}[F]^{2}\right) S\right]}{k_{1} k_{3}\left[P_{1}\right]+k_{5}\left(k_{2}[F]+k_{1}[H]\right)}
$$

where $\mathrm{k}_{\mathrm{x}}$ is the rate coefficient for the $\mathrm{x}$-th surface reaction showed in table $\mathrm{I},[\mathrm{H}],[\mathrm{F}]$, and $\left[\mathrm{P}_{1}\right]$ are the molar concentration of atomic hydrogen, atomic fluorine and $\mathrm{B}-$ precursor $\left(\mathrm{BF}, \mathrm{BF}_{2}\right.$ or $\mathrm{BF}_{3}$ ), respectively, in units of $\left[\mathrm{mol} \mathrm{cm}{ }^{-3}\right]$ and, for $\mathrm{hBN}$, the total concentration of surface sites is $[\mathrm{S}]=7.9 \times 10^{9} \mathrm{~mol} \mathrm{~cm}^{-2}$. The rate constants, $\mathrm{k}_{\mathrm{x}}-$ in the Arrhenius form, were estimated to obtain 
good fits assuming either $\mathrm{BF}_{3}, \mathrm{BF}_{2}$, or $\mathrm{BF}$ as possible precursors, and are then examined here for their ability to also capture the trends seen in the arcjet studies.

The predicted hBN growth rate variation with gas flow, depending on what is assumed to be the boron-containing precursor, for experimental volume flow rates of source and injected gas are compared to those measured experimentally in figure 2.

We see that the model captures the general results seen experimentally for the $\mathrm{BF}, \mathrm{BF}_{2}$ and $\mathrm{BF}_{3}$ precursor, and furthermore, is within a factor of $2-5$ of the absolute growth rates measured, depending on what is chosen to be the precursor.

The two most significant findings in the present study are: (i) gas-phase radicals other than $\mathrm{BF}_{3}$ and $\mathrm{N}_{2}$ can be growth precursors, and (ii) the possible role of atomic hydrogen in the deposition of boron nitride in the $B / N / H / F$ system may be more important than previously suspected, and that in certain growth regimes, the heterogeneous reactions involving atomic hydrogen can be the growth-rate limiting reactions.

Using the surface mechanism with the estimated rate constants, the surface composition is dominated by chemisorbed $\mathrm{B}$ - and $\mathrm{N}$ - containing species (surface sites $R$ ), still incompletely incorporated into the underlying bulk crystalline structure.

Table I: hBN surface mechanism.

\begin{tabular}{|l||l|}
\hline Reaction & \multicolumn{1}{c|}{$\begin{array}{c}\text { Rate coefficient } \\
{\left[\mathrm{cm}^{3} \mathrm{~mol}^{-1} \mathrm{~s}^{-1}\right]}\end{array}$} \\
\hline \hline $\mathrm{SF}+\mathrm{H} \rightarrow{ }^{\mathrm{k} 1} \mathrm{~S}^{*}+\mathrm{HF}$ & $\mathrm{k}_{1}=3.16 \times 10^{11} \mathrm{~T}^{0.5}$ \\
\hline $\mathrm{S}^{*}+\mathrm{F} \rightarrow{ }^{\mathrm{k} 2} \mathrm{SF}$ & $\mathrm{k}_{2}=3.16 \times 10^{12} \mathrm{~T}^{0.5}$ \\
\hline $\mathrm{P}_{1}+\mathrm{S}^{*} \rightarrow{ }^{\mathrm{k} 3} \mathrm{P}^{*}{ }_{1}$ & $\mathrm{k}_{3-\mathrm{BF}}=2.61 \times 10^{13} \mathrm{~T}^{0.5} \exp (-2959.46 / \mathrm{RT})$ \\
& $\mathrm{k}_{3-\mathrm{BF} 2}=2.19 \times 10^{13} \mathrm{~T}^{0.5} \exp (-8270.47 / \mathrm{RT})$ \\
\hline $\mathrm{P}_{2}+\mathrm{P}^{*}{ }_{1} \rightarrow{ }^{\mathrm{k} 4} \mathrm{RF} 3=1.86 \times 10^{11} \mathrm{~T}^{0.5} \exp (-23255.73 / \mathrm{RT})$ \\
\hline $\mathrm{R}+\mathrm{H} \rightarrow{ }^{\mathrm{k} 5} \mathrm{hBN}+\mathrm{S}^{*}+$ Products & $\mathrm{k}_{4}>>\mathrm{k}_{3}$ \\
\hline $\mathrm{F}+\mathrm{R} \rightarrow{ }^{\mathrm{k} 6} \mathrm{PF}$ & $\mathrm{k}_{5}=3.87 \times 10^{10} \mathrm{~T}^{0.5}$ \\
\hline $\mathrm{PF} \rightarrow{ }^{\mathrm{k} 7} \mathrm{~S}^{*}+$ Products & $\mathrm{k}_{6}=2.06 \times 10^{13} \mathrm{~T}^{0.5}$ \\
\hline
\end{tabular}
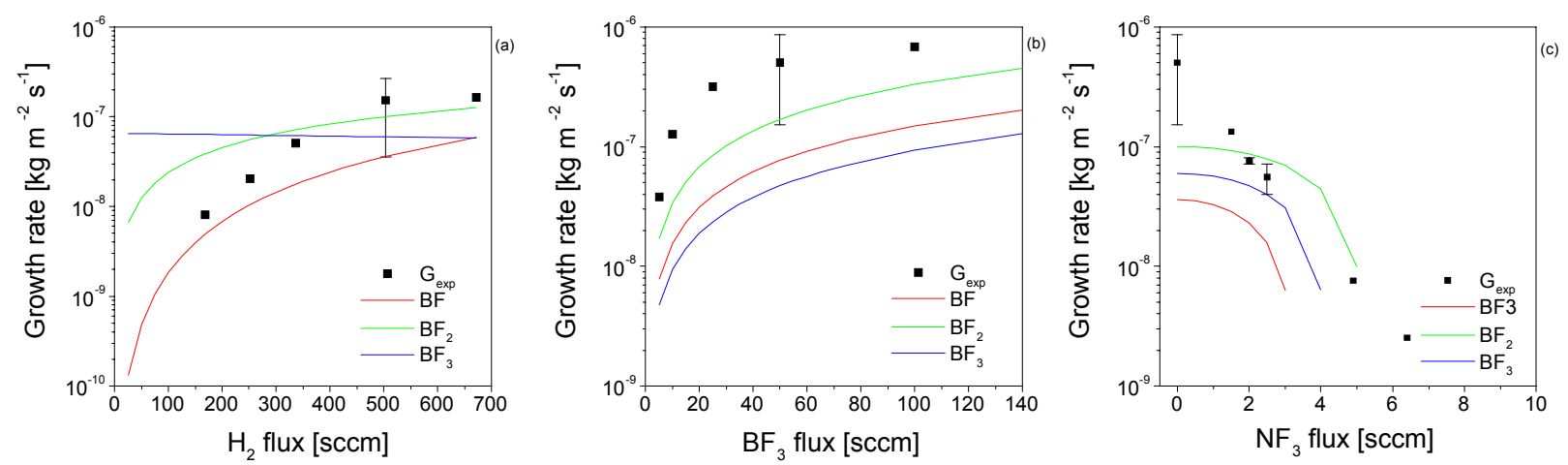

Figure 2: Growth rate as function of gas flux for $\mathrm{N}_{2}=7 \mathrm{slm}, \mathrm{BF}_{3}=50 \mathrm{sccm}$, and $\mathrm{NF}_{3}=50 \mathrm{sccm}$ (figure 2a), $\mathrm{N}_{2}=7 \mathrm{slm}, \mathrm{H}_{2}=504 \mathrm{sccm}$, and $\mathrm{NF}_{3}=50 \mathrm{sccm}$ (figure 2b), $\mathrm{N}_{2}=7 \mathrm{slm}$, $\mathrm{H}_{2}=504 \mathrm{sccm}, \mathrm{BF}_{3}=50 \mathrm{sccm}$ (figure $2 \mathrm{c}$ ), respectively and $\mathrm{p}=235 \mathrm{mtorr}$. 


\section{CONCLUSIONS}

A one-dimensional gas-phase kinetic mechanism for $\mathrm{Ar} / \mathrm{B} / \mathrm{F} / \mathrm{N} / \mathrm{H}$ system was presented to describe the gas-phase chemistry for growth of $\mathrm{hBN}$. We have shown that the gas-phase is removed from chemical equilibrium, and that many radicals other than the source gases can account for the measured $\mathrm{hBN}$ growth rates

A simple surface mechanism was proposed, based on the role that hydrogen might play in the abstraction of surface fluorine and fluorine atoms etches the hBN. The growth rates predicted by the surface mechanism are in very good agreement with the growth rates seen in the experiments, when reasonable estimates for the surface reaction rate constants are made.

\section{AKNOWLEDGMENTS}

P. R. P. Barreto acknowledges fellowship support from FAPESP and to CENAPAD for the provision of computational facilities.

\section{REFERENCES}

1. W. Kalss, R. Haubner, and B. Lux, Diamond and Related Materials, 7, 369, (1998).

2. O. Dugne, S. Prouhet, A. Guette, and R. Naslain, J. of Alloy and Compounds, 176, 187, (1991).

3. H. Hannache, R. Naslain, C. Bernard, and L. Heraud, Proc. Forth European Conference on Chemical Vapour Deposition, 305, (1983).

4. S. Matsumoto, N. Nishida, K. Akashi, and K. Sugai, J. Mat. Sci., 31, 713, (1996).

5. H. Hannache, R. Naslain, and C. Bernard, J. Less-Common Met., 95, 221, (1983).

6. H. McDaniel and M. D. Allendorf, J. Phys. Chem. A, 102, 7804, (1998).

7. M. D. Allendorf and C. F. Melius, J. Phys. Chem. A, 101, 2670, (1997).

8. P. R. P. Barreto and M. A. Cappelli (private communication).

9. S. Prouhet, F. Langlais, A. Guette, and R. Naslain. Eur. J. Solid State Inorg. Chem., 30:953, 1993.

10. S. Prouhet, G. Vignoles, F. Langlais, A. Guette, and R. Naslain. Eur. J. Solid State Inorg. Chem., 30:971, 1993.

11. P. R. P. Barreto, M. A. Cappelli and S. Matsumoto, International Conference on Plasma Physics, Quebec City, CA, (2000).

12. P. R. P. Barreto, A.E. Kull, M.A. Cappelli, $6^{\circ}$ Encontro Brasileiro de Física dos Plasmas, 31 , Campos do Jordão, SP, Brazil, Dez. 2000.

13. P. R. P. Barreto, $6^{\circ}$ Encontro Brasileiro de Física dos Plasma, 30, Campos do Jordão, SP, Brazil, Dez. 2000.

14. P. R. P. Barreto (INPE - internal report).

15. S. J. Harris and A. M. Weiner., Appl. Phys. Lett., 53, 1605 (1988).

16. S. J. Harris, J. Appl. Phys. 65, 3044 (1989).

17. D. G. Goodwin and G. G. Gavillet, J. Appl. Phys. 68, 6393 (1990).

18. R. J. Kee, F. M. Rupley, and J. A. Miller, Technical Report SAND89-8009, Sandia National Laboratories (1990).

19. Wn.C. Reynolds, (private communication).

20. M. Frenklack and K.E. Spear, J. Material Research 3, 133 (1988). 